Original Article

\title{
FORMULATION AND EVALUATION OF SOLID DISPERSION TABLETS OF FUROSEMIDE USING POLYVINYLPYRROLIDONE K-30
}

\author{
EMAN HUSSAIN ELMUBARAK ${ }^{1 *}$, ZUHEIR ABDELRAHMAN OSMAN ${ }^{2}$, MOHAMMED ABDELRAHMAN ${ }^{1}$
}

1Department of Pharmaceutics, Faculty of Pharmacy, University of Gezira, Wad Madani, Sudan, ${ }^{2}$ Department of Pharmaceutics, Faculty of Pharmacy, University of Khartoum, Khartoum, Sudan

Email: emanelhassan26282@gmail.com

Received: 08 Nov 2020, Revised and Accepted: 10 Jan 2021

ABSTRACT

Objective: The objective of the present study was to improve the aqueous solubility and dissolution characteristics of the loop diuretic furosemide (FUR); a class IV drug in the Biopharmaceutical Classification System (BCS) using solid dispersion technique.

Methods: Solvent evaporation and kneading methods were used to produce solid dispersions of FUR in different ratios with the hydrophilic carrier polyvinylpyrrolidone K-30 (PVP-K30). The prepared solid dispersions were evaluated in terms of solubility study, percentage yield, drug content and Fourier transform infrared spectroscopic study (FT-IR). Tablets containing the optimized formula of solid dispersions $\left(\mathrm{SD}_{\mathrm{S3}}\right)$ were formulated and their dissolution characteristics were compared with commercial furosemide tablets.

Results: The prepared solid dispersions showed an increase in aqueous solubility, especially those formulated in a 1:2 drug: carrier ratio using solvent evaporation method $\left(\mathrm{SD}_{\mathrm{S3}}\right)$, it showed a four-fold increase in solubility compared to the parent drug. The absence of drug-carrier chemical interactions that could affect the dissolution was proved by FT-IR. Solid dispersion tablets exhibited a better dissolution profile in simulated gastric fluid $\mathrm{pH} 1.2$ at $37^{\circ} \mathrm{C} \pm 0.5$ than the commercial FUR tablets in terms of mean dissolution time $(8.44 \mathrm{~min})$ and dissolution efficiency in 30 min (42.54\%). Both FUR solid dispersions and commercial tablets followed Weibull and Krosmeyer models as the two best models of drug release kinetics proving that they were immediate release.

Conclusion: According to the results obtained in this study, solid dispersion techniques could be successfully used for the enhancement of aqueous solubility and dissolution rate of FUR.

Keywords: Furosemide, Solid dispersion, Polyvinylpyrrolidone K-30 (PVP-K30), Solvent evaporation, Kneading, Dissolution enhancement (C) 2021 The Authors. Published by Innovare Academic Sciences Pvt Ltd. This is an open access article under the CC BY license (https://creativecommons.org/licenses/by/4.0/) DOI: https://dx.doi.org/10.22159/ijcpr.2021v13i2.41554. Journal homepage: https://innovareacademics.in/journals/index.php/ijcpr

\section{INTRODUCTION}

Oral drug delivery, especially oral solid dosage forms such as tablets and capsules are the most desired administration route for many drugs, due to its several advantages over other formulations. It is the most commonly used route due to its greater stability, ease of administration, high patient compliance, the accuracy of doses, costeffectiveness, and flexibility of dosage form design [1]. The bioavailability and therapeutic effectiveness of a drug administered by oral route depend on several factors, including aqueous solubility, drug permeability, dissolution rate, systemic metabolism, and susceptibility to efflux mechanisms. The most causes of low oral bioavailability are poor solubility and low permeability. Dissolution may be the rate-determining step for drug absorption, bioavailability, and thus for the onset of therapeutic activity. The dissolution rate is a function of the solubility and surface area of a drug $[2,3]$. Solubility is one of the most important parameters to achieve the desired drug concentration in systemic circulation to attain the required pharmacological response. Poorly water-soluble drugs often require higher doses to reach therapeutic plasma concentrations after oral administration, also, they have slow drug absorption that leads to inadequate and variable bioavailability [2] The improvement of drug solubility, thereby its oral bioavailability, remains one of the most challenging aspects of the drug development process, especially for an oral-drug delivery system. There are many approaches to increase the solubility of a poorly water-soluble drug and thus improve its bioavailability, such as grinding, use of surfactants, salt formation, $\mathrm{pH}$ adjustments, prodrugs, complexation with cyclodextrins, self-emulsifying formulations, micronization, emulsions and liposomes [4].

Solid dispersion is one of the most promising, viable, and economic techniques that can potentially enhance the aqueous solubility and the dissolution rate of hydrophobic drugs. The concept of using solid dispersions was first introduced by Sekiguchi and Obi in 1961. They demonstrated that the eutectic mixture of sulfathiazole and the physiologically inert water-soluble carrier urea exhibited higher absorption and excretion after oral administration than sulfathiazole alone [5]. As reported by Sridhar, et al., the term solid dispersion refers to a group of solid products consist of at least two components, a hydrophilic matrix and a hydrophobic drug, where the drug can be dispersed molecularly or in the amorphous state [6]. The matrix can be either crystalline or amorphous. When the solid dispersions product is exposed to an aqueous media, the carrier dissolves and the drug is released as fine colloidal particles with an enhanced surface area that produces a higher dissolution rate and improved bioavailability. The improvement of the dissolution of drugs from solid dispersions is based mainly on three different mechanisms: the reduction in particle size and increased surface area, the wettability of the drug, which is improved by direct contact with the hydrophilic matrix, and the conversion of the crystalline state to the more soluble amorphous state [7]. There are many techniques for solid dispersions preparation, such as solvent casting method, kneading, co-precipitation method, melting method, cogrinding, gel entrapment technique, spray drying, melt extrusion, lyophilization and dropping method solution [8]. Solvent evaporation is one of the most used methods as the drug is usually dispersed within the hydrophilic matrix at the molecular level. The technique involves solubilization of the drug and polymer in a solvent or a mixture of solvents such as ethanol, methanol, chloroform, or dichloromethane, which is then evaporated. The solvent must solubilize both the carrier and the drug, and it should be completely removed; the resulting film can be pulverized and milled. Evaporation occurs at low temperatures by different techniques such as vacuum drying, mixture heating, application of filtration or heating bath, supercritical fluid, rotary evaporation, and spray-drying $[4,9]$. Kneading technique is one of the complex 
formation-based techniques. It is based on the wetting of the carrier with water or hydro-alcoholic solution to form a paste. The drug is then added and kneaded for a specified period. The kneaded mixture is then dried and passed through a sieve if necessary. Kneading method is the most common and simple method used to prepare the inclusion complexes, it has a low cost of production in both laboratory and large scale [2].

The selection of the carrier influences the dissolution characteristics of the dispersed drug since the dissolution rate of one component from the surface is affected by the other component in the multiple component mixtures. Therefore, various hydrophilic carriers, such as polyethylene glycols (PEGs), polyvinylpyrrolidone (PVP), hydroxypropyl methylcellulose (HPMC), gums, sugar, mannitol, and urea have been used for the improvement of dissolution characteristics and bioavailability of poorly aqueous soluble drugs [10].

Furosemide (FUR) is a potent loop diuretic used in the treatment of cardiac, renal, and hepatic failures and in the treatment of hypertension. Based on solubility, oral absorption, and permeability data, FUR is classified as class IV of the Biopharmaceutics Classification System (BCS). It has low solubility and low permeability due to the carboxyl and sulfonamide groups in the structure, with pKa of 3.8 and 9.6, respectively (fig. 1). The bioavailability problems, reported as a result of variable and erratic gastrointestinal absorption, are probably due to the low and $\mathrm{pH}$-dependent solubility together with various existing polymorphic forms of FUR [11]

This study aims to improve the solubility and dissolution rate of FUR by preparing solid dispersion with PVP K-30 employing two preparation methods, solvent evaporation and kneading technique, also, it has an objective to evaluate the potential of solid dispersions for the development of FUR solid dispersion tablets.<smiles>NS(=O)(=O)c1cc(C(=O)O)c(NCc2ccco2)cc1Cl</smiles>

Fig. 1: Chemical structure of FUR

\section{MATERIALS AND METHODS}

Furosemide (FUR) was gifted kindly by Blue Nile Pharmaceutical Factory (Khartoum, Sudan). Polyvinyl pyrrolidone (PVP K-30) magnesium stearate, talc powder, and lactose monohydrate were obtained from Amipharma Laboratories Ltd. (Khartoum, Sudan). Microcrystalline cellulose 102 (MCC 102) and cross carmellose sodium were gifted kindly by Humavit Drugs international Co. Ltd. (Khartoum, Sudan). Absolute ethanol was obtained from Sd-FineChem. Ltd. (India). Concentrated Hydrochloric acid (HCl 37\%) was obtained from ATOM SCIENTIFIC ${ }^{\circledR}$ (UK). Methanol was purchased from LOBA CHEMIE Pvt. Ltd (Mumbai, India). Distilled water is used throughout the study and all other materials and chemicals were of analytical grade. Brand ${ }^{\circledR}$ A and brand ${ }^{\circledR}$ B containing furosemide 40 mg were obtained from the local drug market in Sudan.

\section{Preparation of solid dispersions}

\section{Solvent evaporation method}

FUR solid dispersions were prepared by a solvent evaporation method using PVP K-30 in different ratios (1:0.5, 1:1 and 1:2 of the drug: polymer). A minimal amount of methanol was used to dissolve the required amount of FUR and the carrier by continuous stirring with a magnetic stirrer (Stuart ${ }^{\circledR}, \mathrm{UK}$ ) for one hour at room temperature. The solvent was completely removed under reduced pressure using a rotary evaporator (SENCO Technology Co., Ltd, China) kept at $40{ }^{\circ} \mathrm{C}$. The solid dispersions formed were further dried in an oven (Nuve ${ }^{\circledR}$, Turkey) at $40^{\circ}$ for $24 \mathrm{~h}$. All the resulting solid dispersions were scraped, pulverized in a mortar and sieved through a 60-mesh sieve. Following that, all solid dispersions were stored in amber glass bottles and kept in the desiccator until further use [12].

\section{Kneading method}

A mixture of FUR and PVP-K30 (1:0.5, 1:1 and 1:2 by weight) was wetted using a small amount of water-ethanol solution (in 1:1 ratio) and kneaded thoroughly for $30 \mathrm{~min}$ in a glass mortar. The paste formed was dried for $24 \mathrm{~h}$ in an oven at $40{ }^{\circ} \mathrm{C}$. Dried mass was pulverized and passed through sieve No. 60 and stored in amber glass bottles and kept in the desiccator until further use [13].

\section{Evaluation of FUR solid dispersions}

\section{Percentage of practical yield}

The percentage of practical yield is calculated to know about the efficiency of the solid dispersion preparation method, it helps in the selection of a suitable method of production. Solid dispersions of FUR were collected and weighed to determine practical yield from the following equation [14].

$$
\text { Practical Yield (\%) }=\frac{\text { Practical mass (solid dispersion) }}{\text { Theoratical mass (Drug+carrier) }} \times 100
$$

\section{Drug content}

Solid dispersions containing an equivalent amount of $10 \mathrm{mg}$ of FUR were weighed accurately and dissolved in $10 \mathrm{ml}$ methanol. $2.5 \mathrm{ml}$ of aliquots were withdrawn and diluted into $25 \mathrm{ml}$ volumetric flask with distilled water. The sample was filtered through Whatman filter paper then $0.45 \mu \mathrm{m}$ cellulose nitrate membrane filter, diluted and assayed for FUR spectrophotometrically by UV at $245 \mathrm{~nm}$. Using methanol: distilled water as blank. The drug content was calculated from the calibration curve constructed at concentration range between 5 and $25 \mu \mathrm{g} / \mathrm{ml}$ as follows:

$$
\% \text { Drug content }=\frac{\text { Practical amount of solid dispersion }}{\text { Theoretical amount of solid dispersion }} \times 100
$$

\section{Solubility study}

An excess amount of pure FUR and solid dispersions were added to $25 \mathrm{ml}$ stopper conical flasks containing distilled water, completed to the mark separately and the samples were rotated for $24 \mathrm{~h}$ in shaking incubator (BioFree ${ }^{\circledR}$, Japan) at $25^{\circ} \mathrm{C}$. The mixtures were filtered through Whatman filter paper then $0.45 \mu \mathrm{m}$ cellulose nitrate membrane filter. The filtrates were suitably diluted with distilled water and analyzed spectrophotometrically at $245 \mathrm{~nm}$ using UV/VIS Spectrophotometer (model 7315 Jenway ${ }^{\circledR}$, England) for detection of FUR. Measurement was carried out in triplicate and the average solubility was calculated [3].

\section{Fourier transforms infrared (FT-IR) study}

FT-IR spectra of moisture-free powdered samples of FUR, PVP-K30, and solid dispersions were recorded using Shimadzu IR Tracer-100 (Kyoto ${ }^{\circledR}$, Japan). Samples of 2-3 mg were mixed with about $400 \mathrm{mg}$ of dried potassium bromide $(\mathrm{KBr})$ then compressed into transparent disks utilizing a hydrostatic press at 6-8 tons pressure. The scanning range was from 500 to $4000 \mathrm{~cm}^{-1}$ at a resolution of $4 \mathrm{~cm}^{-1}$ [13].

\section{Pre-compression evaluation}

Based on solubility performance, the formula with the highest solubility result was selected for the preparation of FUR solid dispersion tablets and the flow characteristics of the powder sample were evaluated to ensure the tableting ability.

\section{The angle of repose}

The angle of repose is defined as the maximum angle possible between the surface of the pile of the powder and the horizontal plane. The angle of repose is designed by $\theta$ and given by the flowing equation:

$$
\operatorname{Tan} \theta=\mathrm{h} / \mathrm{r} \text { or } \theta=\operatorname{Tan}^{-1(\mathrm{~h} / \mathrm{r})}
$$

Where $h$ is the height of the pile $(\mathrm{cm})$ and $\boldsymbol{r}$ is the radius of the base of the pile $(\mathrm{cm})$. 
The lower the angle of repose, the better is the flow properties, and generally angle of repose from 25 up to $35^{\circ}$ results in excellent to good flow properties [15].

\section{Compressibility index (Carr's Index)}

It is one of the measurements that indicate powder flow properties. It is expressed in percentage and given as,

$$
\text { Carr's index }(\%)=(\mathrm{Dt}-\mathrm{Db}) / \mathrm{Dt} \times 100
$$

Where $D t$ and $D b$ are the tapped and bulk densities of the powder, respectively. In general, Compressibility index values from 5 up to $15 \%$ indicate excellent to good flow properties [15].

\section{Formulation of FUR solid dispersion tablets}

Tablets containing solid dispersions equivalent to $40 \mathrm{mg}$ of FUR were prepared by direct compression method using different formulation excipients such as microcrystalline cellulose (MCC102) as binder, crosscarmellose sodium as a disintegrant, magnesium stearate $(0.5 \% \mathrm{w} / \mathrm{w})$ as a lubricant, talc $(1.5 \% \mathrm{w} / \mathrm{w})$ as a glidant and lactose monohydrate as a filler to adjust the weight of the tablets into $220 \mathrm{mg}$. All the ingredients required were weighed individually and screened through a 60-mesh sieve before mixing to ensure uniform particle size distribution. The blend was compressed on a single tableting press machine (Erweka ${ }^{\circledR}$, Germany) equipped with an $8 \mathrm{~mm}$ round flat punch set. Tablets were stored in an airtight container for further studies.

\section{Post compression evaluation of FUR solid dispersion tablets}

\section{Tablet thickness}

The thickness of tablets was determined using Vernier caliper tester. (AEROSPACE $®$, China). Ten individual tablets were selected randomly and used; the average values were calculated. The thickness of a tablet should be controlled within $\pm 5 \%$ variation of a standard value depending on the size of the tablet [16].

\section{Weight variation test}

Weight variation was measured on twenty randomly selected tablets using an electronic analytical balance (KERN $®$, Germany), the tablets were weighed individually and then collectively, the average weight of the tablets and percentage of weight variation were calculated. The USP limit for \% deviation is $7.5 \%$ for uncoated tablets weighing 130 $324 \mathrm{mg}$, and not more than two of the individual weights of tablets should deviate from the average weight [17].

\section{Tablet hardness}

The hardness of tablets was tested on ten randomly selected tablets using a hardness tester (Guoming ${ }^{\circledR}$, China). The force required to break the tablet was measured in $\mathrm{Kg} / \mathrm{cm}^{2}$ and an average value was calculated [16].

\section{Tablet friability}

Friability \% was determined using twenty tablets selected randomly from the batch. Tablets were weighed (W1) and placed into the plastic drum of a stabilator (Guoming ${ }^{\circledR}$, China) rotated at $25 \mathrm{rpm}$ for $4 \mathrm{~min}$. The excess dust was removed from the tablets and they were reweighted (W2) for calculation of friability (\%) [16]. The friability value of the tablets less than $1 \%$ is considered acceptable for most pharmaceutical tablets according to USP.

$$
\text { Friability } \%=(\mathrm{W} 1-\mathrm{W} 2) / \mathrm{W} 1 \times 100
$$

\section{Drug content determination}

For this test, ten tablets were selected randomly and powdered in a mortar. The amount of powder equivalent to $10 \mathrm{mg}$ of FUR was dissolved in $25 \mathrm{ml}$ methanol by sonication for $15 \mathrm{~min}$ and filtered through Whatman filter paper, then $0.45 \mu \mathrm{m}$ cellulose nitrate membrane filter. Suitable dilutions were made, and the drug content was analyzed spectrophotometrically at $245 \mathrm{~nm}$ using a UV-VIS spectrophotometer (model 7315 Jenway ${ }^{\circledR}$, England). Each measurement was carried out in triplicate and the average drug content was calculated [17].

\section{Disintegration time}

A disintegration test was conducted in vitro using a Digital tablet disintegration test apparatus (SCIENTIFIC ${ }^{\circ}$, India). It consists of a basket-rack assembly containing six open-ended transparent tubes of USP-specified dimensions, held vertically upon a 10 -mesh stainless steel wire screen. To test for disintegration time, one tablet was placed in each tube of the disintegration apparatus and the basket rack was positioned in $0.1 \mathrm{~N} \mathrm{HCl} \mathrm{pH} 1.2$ at $37 \pm 2{ }^{\circ} \mathrm{C}$. A standard motor-driven device was used to move the basket assembly containing the tablets up and down, the device was operated until all tablets were disintegrated, and all particles were passed through the 10-mesh screen in the time specified. $15 \mathrm{~min}$ is considered the disintegration time for most normal release tablets [17]

\section{In vitro dissolution study}

In vitro dissolution study of FUR solid dispersion tablets and two commercially available brands of FUR in Sudan (brand A and B) was performed in a paddle-type dissolution apparatus USP II RC-6 Dissolution tester (Gouming ${ }^{\circledR}$, China) equilibrated at $37 \pm 0.5^{\circ} \mathrm{C}$ and $100 \mathrm{rpm}$ speed. The dissolution study was carried out in triplicate for one hour in $900 \mathrm{ml}$ of Simulated Gastric Fluid (SGF, pH 1.2) Dissolution samples $(10 \mathrm{ml})$ were collected at $5,10,15,20,30,45$, and $60 \mathrm{~min}$ and replaced with an equal volume of SGF solution to maintain the volume constant. The sample solution was filtered and analyzed by a UV/VIS spectrophotometer (model 7315 Jenway ${ }^{\circledR}$, England) at $245 \mathrm{~nm}$ [18].

Dissolution profile comparison between formulated solid dispersion tablets and two marketed brands of FUR

\section{Model-independent approach}

The dissolution profiles of the optimized FUR solid dispersions, brand $A \circledR$ and brand $B \circledR$ tablets were compared using three modelindependent parameters $\% \mathrm{DE}_{30}$ (Dissolution Efficiency at $30 \mathrm{~min}$ ), similarity factor $\left(\mathrm{f}_{2}\right)$ and mean dissolution time (MDT).

\section{Dissolution efficiency at $30 \mathrm{~min}$. (\%DE $\left.\mathrm{DE}_{30}\right)$}

For each sample, the percentage dissolutionfiefency at $30 \mathrm{~min}$. was calculated as the percentage ratio of the area under the dissolution curve up to $30 \mathrm{~min}$. to that of the area of the rectangle described by $100 \%$ dissolution at the same time point. Dissolution efficiency (\%DE) can be calculated from the following equation [19]:

$$
\% D E=\frac{\int_{t 1}^{t 2} y \cdot d t}{y 100\left(t_{2}-t_{1}\right)} \times 100
$$

Where $y$ is the percentage of the dissolved product. \%DE is then the area under the dissolution curve between time points $t_{1}$ and $t_{2}$ expressed as a percentage of the curve at maximum dissolution y100 over the same time. In the current study $t_{1}=0$ and $t_{2}=30 \mathrm{~min}$.

\section{Similarity factor $\left(f_{2}\right)$}

The similarity factor $\left(f_{2}\right)$ is one of the fit factors that had been developed by Moore and Flanner in 1996. It contrasts the similarity between FUR dissolved per unit time of a test with that of a reference formulation. $\mathrm{f}_{2}$ can be defined from the following equation [20]:

$$
\mathrm{f}_{2}=50 \log \llbracket 1+\left(\frac{1}{n}\right) \sum_{\mathrm{t}=1}^{\mathrm{n}} \mathrm{W}_{\mathrm{t}}\left(\mathrm{R}_{\mathrm{t}}-\mathrm{T}_{\mathrm{t}}\right)^{2} \rrbracket^{-0.5} \times 10
$$

Where $\mathrm{n}$ is the number of withdrawal points, $\mathrm{R}_{\mathrm{t}}$ is the percentage dissolved of reference at the time point $t, T_{t}$ is the percentage dissolved of the test at the time point $t$, and $\mathrm{W}_{t}$ is optional weight at time $t$. A value of $100 \%$ for the similarity factor $\left(f_{2}\right)$ suggests that test and reference profiles are identical. Values between 50 and 100 indicate that the dissolution profiles are similar, while lower $f_{2}$ values imply an increase in dissimilarity between release profiles.

\section{Mean dissolution time (MDT)}

MDT reflects the time for the drug to dissolve and is the first statistical moment for the cumulative dissolution process that provides an accurate drug release rate. A higher MDT value indicates a greater drug retarding ability. To understand the extent of improvement in dissolution rate of FUR from its solid dispersion 
with PVP-K30, the obtained dissolution data of all samples were fitted into the following equation,

$$
M D T_{\text {invitro }}=\frac{\sum_{i=1}^{n} t \operatorname{mid} \times \Delta M}{\sum_{i=1}^{n} \Delta M}
$$

Where $i$ is the dissolution sample number, $n$ is the number of dissolution times, $\mathrm{t}_{\mathrm{mid}}$ is a time at the midpoint between times ti and ti-1, and $\Delta M$ is the amount of furosemide in $\mu \mathrm{g}$ dissolved between times ti and ti-1 [21].

\section{Model-dependent approach}

To clarify the mechanism of release kinetics of FUR from the hydrophilic carrier PVP-K30, in vitro release data were fitted to various mathematical kinetic models as shown in table (1) using a software program called DDSolver which compare different dissolution profiles using model-dependent approaches [22].

Table 1: Mathematical release kinetic models

\begin{tabular}{ll}
\hline Model & Equation \\
\hline Zero-order & $\mathrm{Q}_{\mathrm{t}}=\mathrm{Q}_{0}+\mathrm{K}_{0} \mathrm{t}$ \\
First-order & $\log Q_{\mathrm{t}}=\log Q_{0}-\frac{K t}{20303}$ \\
Higuchi & $\mathrm{Q}=\mathrm{KH} . \mathrm{t}^{1 / 2}$ \\
Hixon-Crowell & $\sqrt[3]{\mathrm{W} 0}-\sqrt[3]{\mathrm{Wt}}=\mathrm{Kt}$ \\
Krosmeyer-Peppas & $\mathrm{M}_{\mathrm{t}} / \mathrm{M}_{\infty}=\mathrm{kKPt}^{\mathrm{n}}$ \\
Weibull & $\mathrm{F}=\mathrm{Fmax} \times\left\{1-\operatorname{Exp}\left[-\left(\left(\mathrm{t}-\mathrm{T}_{\mathrm{i}}\right)^{\wedge} \beta\right) / \alpha\right]\right\}$ \\
\hline
\end{tabular}

Where $Q_{0}$ represents the initial amount of the drug in the solution, $Q_{t}$ represents the amount of the drug released at time $t,\left(K_{0}, K, K H\right.$, and $\mathrm{kKP}$ ) represent release rate constants for each model, $\mathrm{W}_{0}$ represents the initial amount of the drug in the pharmaceutical dosage form, $\mathrm{W}_{\mathrm{t}}$ represents the amount of the drug remains in the pharmaceutical dosage form at time $t, M_{t}$ is the fraction of drug released at time $t$ and $M_{\infty}$ is the fraction of drug released at time $\infty, n$ is the release exponent that describes the drug release operating mechanism and the diffusion pattern if $n \leq 0.45$ corresponds to
Fickian diffusion mechanisms. $0.45<\mathrm{n}<0.89$ to anomalous nonFickian transport, $n=0.089$ to case ii transport and $n>0.89$ to super case ii transport. $\mathrm{F}$ is the fraction of the drug released at time $t, \alpha$ is a scale parameter which defines the time scale of the process, $\beta$ is the shape parameter which characterizes the curve as either exponential $(\beta=1)$ case1, sigmoid, s-shaped with upward curvature followed by a turning point $(\beta>1)$ case 2 , or parabolic with a higher initial slope and after that consistent with the exponential $(\beta<1)$ case 3. $T_{i}$ is the location parameter that represents the lag time before the onset of the dissolution or release process. $\mathrm{F}_{\mathrm{ma}} \mathrm{x}$ is the maximum fraction of the drug released at infinite time.

\section{RESULTS}

\section{Preparation of solid dispersions}

Solid dispersions of FUR were prepared by solvent evaporation and kneading methods using PVP-K30 as a drug carrier. In the present work, six formulations were prepared and coded, their complete composition is shown in table (2). All solid dispersions prepared were found to be fine yellowish powder.

Table 2: Formulations of FUR solid dispersion

\begin{tabular}{lcl}
\hline $\begin{array}{l}\text { Preparation } \\
\text { method }\end{array}$ & Batch code & Drug/carrier ratio \\
\hline \multirow{3}{*}{ Solvent evaporation } & $\mathrm{SD}_{S 1}$ & $1: 0.5$ \\
& $\mathrm{SD}_{S 2}$ & $1: 1$ \\
& $\mathrm{SD}_{S 3}$ & $1: 2$ \\
& $\mathrm{SD}_{\mathrm{K} 1}$ & $1: 0.5$ \\
Kneading method & $\mathrm{SD}_{\mathrm{K} 2}$ & $1: 1$ \\
& $\mathrm{SD}_{\mathrm{K} 3}$ & $1: 2$ \\
\hline
\end{tabular}

\section{Evaluation of FUR solid dispersion}

The results of the percentage practical yield, drug content, and solubility study of all solid dispersions prepared by solvent evaporation, and kneading technique, are concluded in table (3).

Table 3: Practical yield by weight, drug content and solubility of solid dispersion formulations

\begin{tabular}{clll}
\hline Batch code & Practical yield (\%) & Drug content (\%) & Solubility (mg/ml) \\
\hline Pure FUR & - & - & $0.0699 \pm 0.001$ \\
$\mathrm{SD}_{S 1}$ & 95.2 & $97.67 \pm 0.005$ & $0.1101 \pm 0.002$ \\
$\mathrm{SD}_{S 2}$ & 77.6 & $99.63 \pm 0.271$ & $0.1271 \pm 0.051$ \\
$\mathrm{SD}_{S 3}$ & 85.5 & $98.13 \pm 0.007$ & $0.2746 \pm 0.002$ \\
$\mathrm{SD}_{\mathrm{K} 1}$ & 54.9 & $96.63 \pm 0.005$ & $0.1041 \pm 0.002$ \\
$\mathrm{SD}_{\mathrm{K} 2}$ & 75.7 & $98.50 \pm 0.270$ & $0.1169 \pm 0.001$ \\
$\mathrm{SD}_{\mathrm{K} 3}$ & 79.4 & $98.60 \pm 0.002$ & $0.1522 \pm 0.001$ \\
\hline
\end{tabular}

\section{Percentage of practical yield by weight}

The practical yield of all samples was found to be in the range of 54.9-95.2 \%. The maximum yield was found $95.2 \%$ in $\mathrm{SD}_{\mathrm{S} 1}$ formulation, which was prepared with a 1:0.5 drug: carrier ratio by the solvent evaporation method.

\section{Drug content}

The drug content of the prepared solid dispersions was in the range of 96.63-99.63\%, indicating the application of the present methods for the preparation of solid dispersions with high content uniformity. The maximum \% drug content was found $99.63 \%$ in $\mathrm{SD}_{\mathrm{S} 2}$ formulation.

\section{Evaluation of solubility}

All solid dispersions of FUR with PVP-K30 showed an enhanced aqueous drug solubility over pure FUR. The aqueous solubility of FUR at $25{ }^{\circ} \mathrm{C}$ is $0.0699 \mathrm{mg} / \mathrm{ml}$. For comparison, the highest FUR solubility was achieved with solid dispersions prepared by the solvent evaporation method. Among all solid dispersion's formulations, $\mathrm{SD}_{\mathrm{S} 3}$ (1:2 ratio prepared by solvent evaporation method) showed the highest solubility results; $0.2746 \mathrm{mg} / \mathrm{ml}$ resulted in a nearly four-fold increase in the aqueous solubility compared with that of pure FUR. This formula was selected as an optimized formula for the preparation of FUR solid dispersions tablets.

\section{Fourier transforms infrared (FT-IR) study}

The FT-IR spectra of pure FUR, as well as PVP-K30 and solid dispersions, are presented in fig. (2). The spectrum of pure FUR (A) showed four absorption peaks at 3398, 3352, 3286 (due to stretching vibration) and $1670 \mathrm{~cm}^{-1}$ (due to bending vibration) which are related to the amino group, as well as 1561 and $1322 \mathrm{~cm}^{-1}$ which belong to the asymmetric stretching vibration of the carboxyl and sulphonyl groups, respectively. The spectrum of PVP (B) showed important bands at $2954 \mathrm{~cm}^{-1}$ due to $\mathrm{C}-\mathrm{H}$ stretching and $1670 \mathrm{~cm}^{-1}$ due to $\mathrm{C}=\mathrm{O}$. In the spectra of $\mathrm{SD}_{\mathrm{S} 3}(\mathrm{C})$ and $\mathrm{SD}_{\mathrm{K} 3}(\mathrm{D})$, the characteristic peaks of PVP-K30 were present at the same position, whereas peaks due to FUR were absent in $\mathrm{SD}_{\mathrm{S} 3}$ spectra (C) indicating trapping of FUR inside PVP matrix. Lack of any new peaks in the solid dispersions and also no differences in the positions of the absorption bands indicate the absence of significant interactions between FUR and PVP-K30 during solid dispersions preparation and storage. 

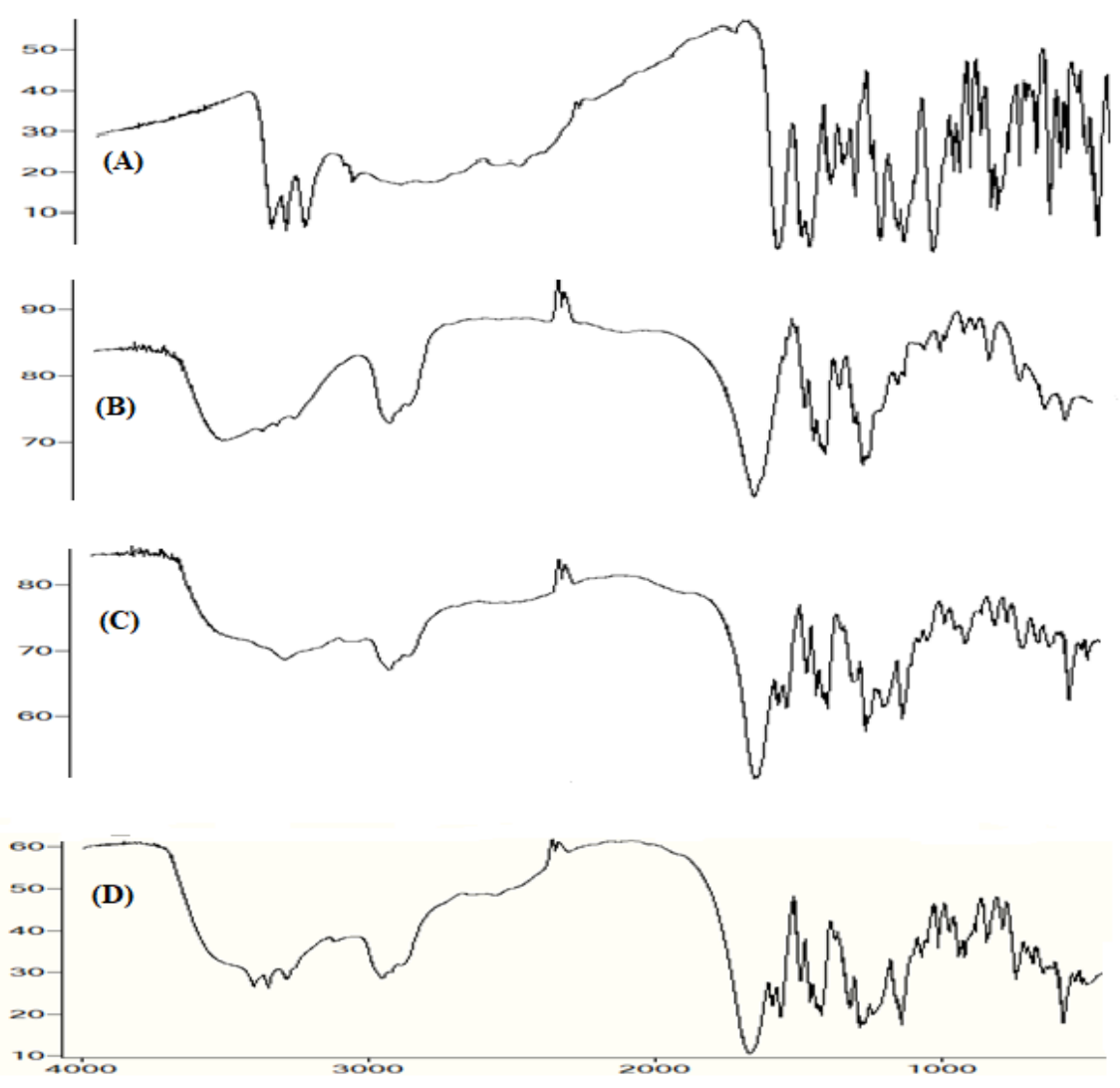

Fig. 2: FT-IR Spectra of $(A)=$ Pure FUR, $(B)=P V P-K 30,(C)=S D_{S 3}$ and $(D)=S D_{K 3}$

\section{Pre-compression evaluation}

Compressibility index (Carr's Index) and the angle of repose of the $\mathrm{SD}_{\mathrm{S} 3}$ sample were $16.3 \%$ and $32.27^{\circ}$, respectively. These values indicate good compressibility and flow properties making this sample suitable for tableting.

\section{Post compression evaluation of FUR solid dispersion tablets}

\section{Physical characterization}

Tablets prepared from the optimized formula of furosemide solid dispersions $\left(\mathrm{SD}_{\mathrm{S} 3}\right)$ experienced good visual general appearance with normal size, smooth texture, and normal thickness and diameter; they were round yellowish colored tablets with flat and smooth surfaces. The average weight was $216.2 \mathrm{mg} \pm 1.67$ with a very low percentage deviation $(0.571 \%)$. The hardness of the tablets was in the normal range $\left(4.36-5.87 \mathrm{~kg} / \mathrm{cm}^{2}\right)$ with a mean value of 5.171 $\mathrm{kg} / \mathrm{cm}^{2} \pm 0.3848$. Besides, the friability was $0.842 \%$ (less than $1 \%$ ). The disintegration time was less than $15 \mathrm{~min}$ and, the drug content was $100.44 \% \pm 4.14$ indicating that the values obtained complied with the USP Pharmacopeial limits.

\section{In vitro dissolution studies}

Dissolution studies were carried out for $\left(\mathrm{SD}_{\mathrm{S} 3}\right)$ tablets and two commercially available brands of FUR in Sudan (brand A and B) according to USP specifications for dissolution. It's recommended that the percentage of API released in $30 \mathrm{~min}$ from immediaterelease tablets using SGF pH 1.2 must be not less than $70 \%$. Dissolution profiles of FUR from $\mathrm{SD}_{\mathrm{S} 3}$, brand $\mathrm{A}$ and brand $\mathrm{B}$ tablets over one hour in SGF pH 1.2 are shown in fig. (3). Mean percentage amount of FUR dissolved from $\left(\mathrm{SD}_{\mathrm{S} 3}\right)$ tablets was $78.03 \%$ within 30 min, while the amount dissolved from brand A and brand $\mathrm{B}$ were $40.45 \%$ and $33.4 \%$, respectively, that means the percent of dissolution of FUR solid dispersions tablets was accepted and its high percentage release highlights the significance of solid dispersions as a technique for improving the dissolution characteristics of poorly soluble drug FUR. It can be observed that the dissolution rate of pure FUR was low in both brands because $46.65 \%$ and $40.34 \%$ of the drug was being dissolved within one hour from Brand A and Brand B, respectively. Double increase in the dissolution rate was found with $\mathrm{SD}_{\mathrm{S} 3}$ tablets, concerning the commercial formulations as $82.24 \%$ was being dissolved over one hour.

Dissolution profile comparison between formulated solid dispersion tablets and two marketed brands of FUR

Model-independent approach

A comparison between the dissolution profiles of FUR from the optimized formula SDS3 and brands (A and B) was made by modelindependent approaches; dissolution efficiency in $30 \mathrm{~min}$ (\%DE30 min), similarity factor (f2) and mean dissolution time (MT). The calculated values of these parameters are presented in table (4). From this table, it is evident that SDS3 tablets showed good dissolution efficiency when compared with the two brands. The values of \%DE30 min for brand A (38.59\%) and brand B (38.46\%) were increased in SDS3 tablets (42.54\%). MDT of FUR in SDS3 tablets was lower ( $8.44 \mathrm{~min}$ ) than those of brand $\mathrm{A}$ and brand $\mathrm{B}$ (13.87 $\mathrm{min}$ and $14.93 \mathrm{~min}$, respectively).

Fit factor, namely; similarity factor (f2) has been accepted by FDA Centre for Drug Evaluation and Research (CDER) (Food and Drug Administration, 1997) as a rating criterion of similarity and difference between two in vitro dissolution profiles. According to the FDA, $f 2$ values greater than 50 should ensure equivalence between the dissolution curves [23].

Fit factor, namely; similarity factor $\left(\mathrm{f}_{2}\right)$ has been accepted by FDA Centre for Drug Evaluation and Research (CDER) (Food and Drug Administration, 1997) as a rating criterion of similarity and difference between two in vitro dissolution profiles. According to the FDA, $f_{2}$ values greater than 50 should ensure equivalence between the dissolution curves [23]. According to this guideline, the release profile curves of FUR corresponding to the optimized formula and 
brands were dissimilar since $f_{2}$ values for the comparison were less than 50 (22.11 and 20.55 for brand $A$ and brand $B$, respectively) The dissolution profile of $\mathrm{SD}_{\mathrm{S} 3}$ tablets were better in terms of \%DE and MDT than the dissolution profiles of the reference brands of FUR. Also, fit factor results showed dissimilarity between the dissolution profiles with superiority to $\mathrm{SD}_{\mathrm{S} 3}$ tablets.

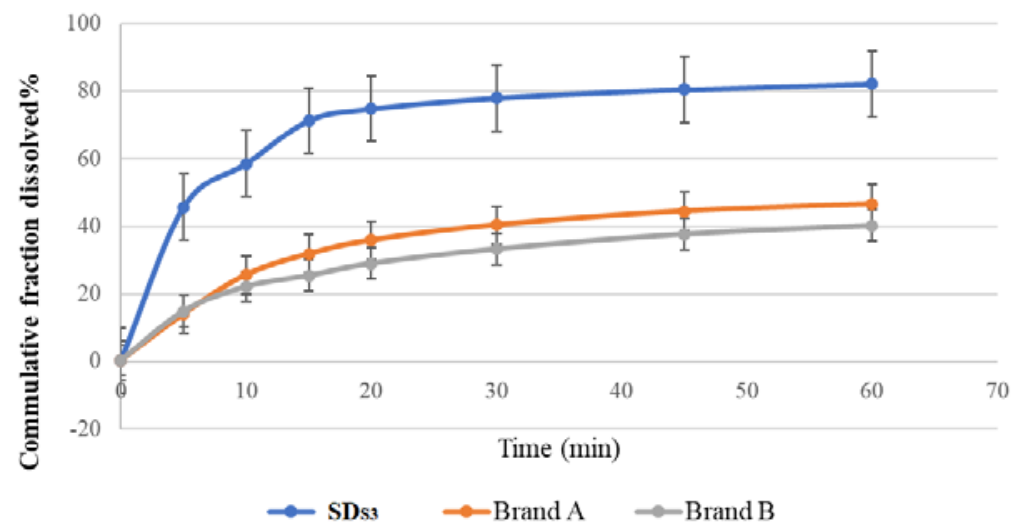

Fig. 3: Dissolution profiles of ( $\left.\mathrm{SD}_{\mathrm{S} 3}\right)$, brand $A$ and brand $\mathrm{B}$ tablets in SGF pH 1.2

Table 4: Parameters of the dissolution profiles comparison using model-independent approaches

\begin{tabular}{clll}
\hline Code & \%DE $_{\mathbf{3 0} \text { min }}$ & MDT (min) & \\
\hline $\mathrm{SD}_{\mathrm{S} 3}$ & 42.54 & 8.44 & $\boldsymbol{f}_{\mathbf{2}}$ \\
Brand A $^{\circledR}$ & 38.59 & 13.87 & 22.11 \\
Brand B $^{\circledR}$ & 38.46 & 14.93 & 20.55
\end{tabular}

\section{Model-dependent approach}

The dissolution profiles corresponding to $\mathrm{SD}_{\mathrm{S} 3}$ tablets and the two reference brands were evaluated bfytting the experimental data to zero-order,first -order, Hixson-Crowell, Higuchi, KrosmeyerPeppas, and Weibull models. The values of the kinetic parameters; adjusted correlation coefficient ( $\mathrm{R}^{2}$ adj), Akaike information criteria (AIC), and model selection criteria (MSC) obtained are shown in table (5). The result showed that the Weibull model had the best fit; as it had the highest $\mathrm{R}^{2}$ adj values, highest (MSC) and lowest (AIC) in all samples of FUR tablets followed by KrosmeyerPeppas model.

Table 5: Values of the kinetic parameters obtained from the models applied to FUR dissolution profiles curve

\begin{tabular}{|c|c|c|c|c|c|c|c|}
\hline Code & Statistics & Zero-order & First-order & Higuchi & Hixon crowell & Krosmeyer peppas & Weibull \\
\hline \multirow{3}{*}{$\mathrm{SD}_{\mathrm{S} 3}$} & $\mathrm{R}^{2}$ adj & 0.4118 & 0.8252 & 0.6830 & 0.7270 & 0.9726 & 0.995 \\
\hline & $\mathrm{AIC}$ & 73.4 & 56.7 & 61.4 & 60.3 & 42.6 & 28.2 \\
\hline & MSC & 0.5940 & 1.4960 & 0.9016 & 1.0494 & 3.253 & 5.0567 \\
\hline \multirow{4}{*}{ Brand $A^{\circledR}$} & $R^{2}$ adj & 0.3445 & 0.6420 & 0.9210 & 0.5546 & 0.9612 & 0.9997 \\
\hline & AIC & 58.3 & 53.4 & 40.9 & 55.2 & 36.5 & -1.87 \\
\hline & MSC & 0.1989 & 0.8173 & 2.3740 & 0.5935 & 2.9311 & 7.7245 \\
\hline & $R^{2}$ adj & 0.3411 & 0.5853 & 0.9424 & 0.5112 & 0.9907 & 0.9984 \\
\hline \multirow[t]{2}{*}{ Brand $\mathrm{B}^{\circledR}$} & $\mathrm{AIC}$ & 55.3 & 51.5 & 34.9 & 52.8 & 21.7 & 6.77 \\
\hline & MSC & 0.1845 & 0.6545 & 2.7313 & 0.4874 & 4.3750 & 6.2466 \\
\hline
\end{tabular}

Table 6 presents the values of the best-fit parameters of the Krosmeyer-Peppas and Weibull model. The values of release exponent (n) extracted from the equations proposed by the Krosmeyer-Peppas model was $<0.45$ for all samples, it suggested that FUR release is governed by Fickian diffusion; also the values found for release rate constant kKP demonstrate that FUR was released more rapidly from PVP matrix (kKP was 37.8 in solid dispersions tablets). Values of shape parameter $\beta$ extracted from the equation proposed by the Weibull model were less than 1 in all samples, which indicates that the shape of the curves was parabolic, displaying a high initial slope and a consistent exponential character.

Table 6: Best fit values for the parameters of krosmeyer-peppas and weibull models

\begin{tabular}{lllll}
\hline Model & Parameter & & SD $_{\text {S3 }}$ & Brand A $^{\circledR}$ \\
\hline Krosmeyer-Peppas & $\mathrm{n}$ & 0.203 & 0.373 & Brand B $^{\circledR}$ \\
Weibull & $\mathrm{kKP}$ & 37.8 & 10.9 & 0.338 \\
& $\beta$ & 0.744 & 0.609 & 10.3 \\
\hline
\end{tabular}




\section{DISCUSSION}

The rationale of this work was to improve the solubility and dissolution rate of FUR by preparing solid dispersion using the hydrophilic polymer PVP-K30 as a drug carrier employing two preparation methods, solvent evaporation and kneading technique. Solubility enhancement was observed in all solid dispersion formulae compared to pure FUR. Mechanisms for solubility enhancement by solid dispersion include particle size reduction, an increase of surface area, increase in wettability and porosity of the drug due to direct contact with hydrophilic carrier [24]. The most soluble FUR was achieved with solid dispersions prepared by the solvent evaporation method. This may be because the solvent evaporation method results in more uniform molecular dispersions of the drug in the hydrophilic carrier matrix as compared with the kneading technique [3]

It can be noticed that; with increasing the drug: carrier ratio the solubility increased to a great extent due to the enhanced wettability of particles dispersed in the hydrophilic carrier. Our findings in this study are in agreement with the study results of Meenakshi and Khan; they found that solid dispersions of FUR with PVP-K30 prepared by solvent evaporation method in 1:4 drug: carrier ratio enhanced the solubility to a greater extent compared with pure FUR [25]. Soni et al. evaluated the aqueous solubility of FUR solid dispersions prepared by the solvent evaporation method with PEG and PVP-K30, solid dispersions with PVP-K30 in 1:2 ratio showed a 4.5-fold increase in aqueous solubility of FUR compared with pure FUR [12]. Solubility study of FUR solid dispersions with PEG and PVP-K30 prepared by fusion and solvent evaporation method indicated that increasing the concentration of the carrier will enhance the aqueous solubility of the poorly soluble drug; this finding is reported by Patel et al., they found that the solubility of FUR-PVP K30 solid dispersions in a ratio of 1:10 was enhanced by 23-fold compared with poorly soluble FUR [21]

According to solubility performance, solid dispersion prepared by the solvent evaporation method in a ratio of 1:2 FUR: PVP was selected for tablets preparation and evaluation. Dissolution studies for the formulated tablets were carried out according to USP specifications using SGF pH 1.2 and compared with a marketed brand of FUR. Release of FUR from tablets containing $\mathrm{SD}_{\mathrm{S} 3}$ was faster and greater compared with conventional tablets containing FUR. This confirmed the advantages of improved aqueous solubility of FUR in its solid dispersions form, which can be formulated as tablets with better dissolution characteristics. This finding is in accordance with the study carried out by Chaulang et al., who found that tablets prepared from solid dispersions of FUR-Cross PVP exhibited better dissolution profile than commercial tablets [26]. Also, immediaterelease tablets of FUR-PVP solid dispersions have been formulated and evaluated by Akbuga et al., solid dispersions system was prepared by the co-precipitation method and the ratio of FUR: PVP was 1:6. The results were compared with similar tablets prepared by physical mixture, showed significant enhancement in dissolution profile of solid dispersions tablets and the drug release from these tablets was 17 times greater than that from tablets prepared from physical mixture [27].

Enhancement of the dissolution rate in tablets containing solid dispersions system with PVP-K30 can be explained by many factors, including; particle size reduction during solid dispersions process, the lower surface tension effect of the carrier PVP $[13,28]$, the improved drug wetting in the dissolution medium [21] local solubilization in the diffusion layer and consequently larger surface area resulting in increased dissolution rate $[18,29]$.

Regarding the kinetics of drug release, the Weibull model provided the best adjustment curve for both the formulated solid dispersion tablets and the reference brands, with the higher adjusted correlation coeficients ( $\left.\mathrm{R}^{2} \mathrm{adj}\right)$ and smallest AIC values. Better dissolution efficiency and less mean dissolution time for the formulated solid dispersion tablets, when compared to the marketed brand of FUR, highlighted the significance of solid dispersion technique in the enhancement of the dissolution behavior of FUR.

\section{CONCLUSION}

This study showed that solid dispersions of FUR with PVP-K30 in different ratios successfully enhanced the aqueous solubility and dissolution rate of FUR. Solid dispersions prepared by the solvent evaporation method showed more improvement in the solubility than those prepared by the kneading technique, and out of the six prepared formulations $\mathrm{SD}_{\mathrm{S} 3}$ (1:2 drug: carrier ratio prepared by solvent evaporation method) showed a four-fold increase in the aqueous solubility when compared with pure FUR. Characterization studies by FT-IR showed that no chemical interaction was encountered between FUR and the carrier. Tablets with satisfactory properties were formulated from the optimized formula of FUR-PVP solid dispersions and all formulated tablets complied with all quality control tests. Comparison of the in vitro dissolution profiles of FUR solid dispersions tablets with two commercially available brands of FUR in the local markets showed that the dissolution rate of FUR can be enhanced to a great extent by solid dispersions technique; twice increase in the dissolution rate was found with $\mathrm{SD}_{\mathrm{S} 3}$ tablets. Hence FUR-PVP K30 binary mixture could be considered for the formulation of immediate-release tablets of FUR to enhance the dissolution characteristics of the poorly soluble drug upon optimizing drug: carrier ratio that will give the maximum dissolution enhancement without affecting the drug release. In vivo pharmacokinetics study should also be considered.

\section{ACKNOWLEDGEMENT}

The authors are thankful to the Department of Pharmaceutics, Faculty of Pharmacy, University of Gezira for supporting this research work by providing the facilities and requirements of the research.

\section{FUNDING}

$\mathrm{Nil}$

\section{AUTHORS CONTRIBUTIONS}

All the authors have contributed equally.

\section{CONFLICTS OF INTERESTS}

Declared none

\section{REFERENCES}

1. Fridgeirsdottir G, Harris R, Fischer P, Roberts C. Support tools in formulation development for poorly soluble drugs. J Pharm Sci 2016;105:2260-9.

2. Savjani K, Gajjar A, Savjani J. Drug solubility: importance and enhancement techniques. ISRN Pharm 2012;2012:1-10.

3. Yadav B, Tanwar Y. Development, characterization and in vitro evaluation of flurbiprofen solid dispersions using polyethylene glycols as carrier. J Appl Pharm 2016;6:60-6.

4. Frizon F, Josimar de Oliveira E, Maria D, Lina M, Maldonado M. Dissolution rate enhancement of loratadine in polyvinylpyrrolidone K-30 solid dispersions by solvent methods. Powder Technol 2013;235:532-9.

5. Sekiguchi K, Obi N. Studies on the absorption of the eutectic mixture. I. a comparison of the behavior of a eutectic mixture of sulfathiazole and that of ordinary sulfathiazole in man. Chem Pharm Bull 1961;9:866-72.

6. Sridhar I, Doshi A, Joshi B, Wankhede V, Doshi J. Solid dispersions an approach to enhance solubility of poorly watersoluble drug. J Sci Innovative Res 2013;2:685-94.

7. Liu Y, Wang $\mathrm{T}$, Ding $\mathrm{W}$, Dong $\mathrm{C}$, Wang $\mathrm{X}$, Chen J, et al. Dissolution and oral bioavailability enhancement of praziquantel by solid dispersions. Drug Delivery Transl Res 2018;8:580-90.

8. Nikghalb L, Singh G, Singh G, Kahkeshan K. Solid dispersion: methods and polymers to increase the solubility of poorly soluble drugs. J Appl Pharm 2012;2:170-5.

9. Santos L, Soaresb M, Albuquerquea C, Silvaa E, Carneiro A, Ferreira D, et al. Solid dispersion of efavirenz in PVP K-30 by conventional solvent and kneading methods. Carbohydr Polym 2014;104:166-74. 
10. Dewan I, Hossain M, Islam S. Formulation and evaluation of solid dispersions of carvedilol, a poorly water-soluble drug by using different polymers. Int J Res Pharm Chem 2012;2:585-93.

11. De Caro V, Ajovalasit A, Sutera F, Sabatino M, Dispenza C, Murgia D. Development and characterization of an amorphous solid dispersion of furosemide in the form of a sublingual bioadhesive film to enhance bioavailability. Pharmaceutics 2017;9:22.

12. Soni L, Ansari M, Thakre N, Singh A, Bhowmick M, Rathi J. Development and in vitro evaluation of furosemide solid dispersion using different water-soluble carriers. Int J Res Dev Pharm 2017;6:2571-5.

13. Chaulang G, Patil K, Ghodke D, Khan S, Yeole P. Preparation and characterization of solid dispersion tablet of furosemide with crospovidone. Res J Pharm Technol 2008;1:386-9.

14. Mangal G, Gadhave M. Eenhancement of solubility and dissolution rate of furosemide by ternary solid dispersion technique. Int J Adv Pharm 2016;5:140-50.

15. Begum SA, Madhuri V, Padmalath K. Design and evaluation of fast dissolving tablets of roflumilast solid dispersions. Int J Pharm Sci Res 2019;10:599-611.

16. Celik B, Ozdemir S, Barla Demirkoz A, Uner M. Optimization of piribedil mucoadhesive tablets for efficient therapy of Parkinson's disease. Physical characterization and ex vivo drug permeation through the buccal mucosa. Drug Dev Ind Pharm 2017;43:1836-45.

17. Uddin M, Al Mamun A, Tasnu T, Asaduzzaman M. In-process and finished products quality control tests for pharmaceutical tablets according to Pharmacopoeias. J Chem Pharm Res 2015;7:180-5.

18. Siahi-Shadbad M, Ghanbarzadeh S, Barzegar-Jalali M, Valizadeh $\mathrm{H}$, Taherpoor A, Mohammadi G, et al. Development and characterization of solid dispersion for dissolution improvement of furosemide by cogrinding method. Adv Pharm Bull 2014:4:391-9.
19. Khan KA, Rhode CT. Effect of compaction pressure on the dissolution efficiency of some direct compression systems. Pharm Acta Helv 1972;47:594-607.

20. Moore JW, Flanner HH. Mathematical comparison of dissolution profiles. Pharm Technol 1996;20:64-74.

21. Patel R, Patel D, Bhimani D, Patel J. Physicochemical characterization and dissolution study of solid dispersions of furosemide with polyethylene glycol 6000 and polyvinylpyrrolidone K30. Dissolut Technol 2008;17-25. dx.doi.org/10.14227/DT150308P17

22. Zhang Y, Huo M, Zhou J, Zou A, Li W, Yao C, et al. DDSolver an add-in program for modeling and comparison of drug dissolution profiles. AAPS J 2010;12:263-71.

23. Food and Drug Administration. Guidance for industry, testing of immediate-release solid oral dosage forms. U. S. Department of health and human services, center for drug evaluation and research (CDER). U. S. Government Printing of fie: Washington DC; 1997.

24. Démuth B, Nagy Z, Balogh A, Vigh T, Marosi G, Verreck G, et al. Downstream processing of polymer-based amorphous solid dispersions to generate tablet formulations. Int J Pharm 2015;486:1-19.

25. Meenakshi, Khan A. Formulation and evaluation of solid dispersion of furosemide in polyvinyl pyrollidone $\mathrm{K} 30$. Int J Chemtech Res 2017;10:160-71.

26. Chaulang G, Patel P, Hardikar S, Kelkar M, Bhosale A, Bhise S. Formulation and evaluation of solid dispersions of furosemide in sodium starch glycolate. Trop J Pharm Res 2009;8:43-51.

27. Akbuga J, Gürsoy A, Yetimoglu F. Preparation and properties of tablets prepared from furosemide-PVP solid dispersion systems. Drug Dev Ind Pharm 1988;14:2091-108.

28. Vasconcelos T, Sarmento B, Costa P. Solid dispersions as strategy to improve oral bioavailability of poorly water-soluble drugs. Drug Discovery Today 2007;12:1068-75.

29. Leuner C, Dressman J. Improving drug solubility for oral delivery using solid dispersions. Eur J Pharm Biopharm 2000;50:47-60. 